\title{
Gold Nanoparticle-Mediated Delivery of Molecules into Primary Human Gingival Fibroblasts Using ns-Laser Pulses: A Pilot Study
}

\author{
Judith Krawinkel ${ }^{1}$, Maria Leilani Torres-Mapa ${ }^{2}$, Kristian Werelius ${ }^{3}$, Alexander Heisterkamp ${ }^{2}$, \\ Stefan Rüttermann ${ }^{4}$, Georgios E. Romanos ${ }^{5,6}$ and Susanne Gerhardt-Szép ${ }^{4, *}$ \\ 1 Institute of Applied Optics, Friedrich-Schiller-University Jena, Fröbelstieg 1, Jena 07743, Germany; \\ judith.krawinkel@uni-jena.de \\ 2 Institute of Quantum Optics, Gottfried Wilhelm Leibniz University Hannover, Welfengarten 1, \\ Hannover 30167, Germany; torres@iqo.uni-hannover.de (M.L.T.-M.); \\ heisterkamp@iqo.uni-hannover.de (A.H.) \\ 3 Department of Postgraduate Education, J.W. Goethe University, Theodor-Stern-Kai 7, \\ Frankfurt am Main 60590, Germany; werelius@em.uni-frankfurt.de \\ 4 Department of Operative Dentistry, Carolinum Dental University-Institute GmbH, J.W. Goethe University, \\ Theodor-Stern-Kai 7, Frankfurt am Main 60590, Germany; ruettermann@med.uni-frankfurt.de \\ 5 Department of Periodontology, School of Dental Medicine, Stony Brook University, Stony Brook, \\ NY 11794, USA; georgios.romanos@stonybrook.edu \\ 6 Department of Oral Surgery and Implant Dentistry, Carolinum Dental University-Institute GmbH, J.W. \\ Goethe University, Theodor-Stern-Kai 7, Frankfurt am Main 60590, Germany \\ * Correspondence: S.Szep@em.uni-frankfurt.de; Tel.: +49-69-6301-7505
}

Academic Editor: Nicola Pugno

Received: 24 March 2016; Accepted: 16 May 2016; Published: 20 May 2016

\begin{abstract}
Interaction of gold nanoparticles (AuNPs) in the vicinity of cells' membrane with a pulsed laser $(\lambda=532 \mathrm{~nm}, \tau=1 \mathrm{~ns})$ leads to perforation of the cell membrane, thereby allowing extracellular molecules to diffuse into the cell. The objective of this study was to develop an experimental setting to deliver molecules into primary human gingival fibroblasts (pHFIB-G) by using ns-laser pulses interacting with AuNPs (study group). To compare the parameters required for manipulation of pHFIB-G with those needed for cell lines, a canine pleomorphic adenoma cell line (ZMTH3) was used (control group). Non-laser-treated cells incubated with AuNPs and the delivery molecules served as negative control. Laser irradiation (up to $35 \mathrm{~mJ} / \mathrm{cm}^{2}$ ) resulted in a significant proportion of manipulated fibroblasts (up to $85 \%$, compared to non-irradiated cells: $p<0.05$ ), while cell viability (97\%) was not reduced significantly. pHFIB-G were perforated as efficiently as ZMTH3. No significant decrease of metabolic cell activity was observed up to $72 \mathrm{~h}$ after laser treatment. The fibroblasts took up dextrans with molecular weights up to $500 \mathrm{kDa}$. Interaction of AuNPs and a pulsed laser beam yields a spatially selective technique for manipulation of even primary cells such as pHFIB-G in high throughput.
\end{abstract}

Keywords: laser based cell manipulation; human gingival fibroblasts; gold nanoparticles; laser

\section{Introduction}

Molecular delivery methods are key technologies in the biomedical sciences. Despite several physical methodical approaches (ballistic, electricity, iontophoresis, ultrasound, light) the efficient delivery of molecules to cells remains challenging [1,2]. Schneckenburger et al. introduced absorption of laser energy $\left(2.5 \mathrm{MJ} / \mathrm{cm}^{2}\right.$ for $\left.1 \mathrm{~s}\right)$ by phenol red to transfect cells [3]. In order to apply lower radiant exposures (RE) absorbing nanoparticles were utilized to induce plasmonic effects. Short laser 
pulses interact with nanoparticles leading to localized, transient increases of cell permeability without affecting cell viability [2,4]. Lasers interacting with nanoparticles were shown to be able to efficiently deliver molecules into cells [2,4,5]. Jumelle et al. delivered calcein molecules into corneal endothelial cells by carbon nanoparticles activated by a femtosecond laser. The uptake reached median efficiency of $54.5 \%$ with low $(0.5 \%)$ mortality [2]. St-Louis Lalonde et al. compared membrane permeabilization by irradiating AuNPs with ns-laser pulses on- $(532 \mathrm{~nm})$ and off- $(1064 \mathrm{~nm})$ resonance [5]. Another transfection technique described in literature is laser scanning of cells previously incubated with gold nanoparticles (AuNPs), called the GNOME approach. Applying the GNOME technique, Heinemann et al. already described the possibility to deliver green fluorescent proteins into mammalian cells with an efficiency of $43 \%$, while maintaining a high level of cell viability. Compared to conventional transfection techniques the GNOME method enables high-throughput transfection of about 10,000 cells per second [1]. Additionally the cell survival rate is high because the effects of this method are highly localized [1]. Depending on the experimental objectives, the laser parameters can be modified to not only achieve reversible cell perforation but even induce targeted cell apoptosis [1]. Lukianova-Hleb et al. utilized plasmonic nanobubbles generated upon laser irradiation of AuNPs to mechanically eliminate cells and tissue, proposing their method as a precise micro-surgical tool [6]. Besides nanobubbles, laser induced shock-waves were also utilized to deliberately damage cell membranes [7], deliver photosensitizers into biofilms for their eradication [8], or to transfect cells in vivo and in vitro [9].

Incubation of cells with AuNPs leads to the attachment of the particles to the cell membrane. Laser irradiation results in plasmonic effects on the AuNPs, field enhancement around the particles, and increased local heat [10-15]. Utilizing these effects, large cell areas can be irradiated quickly while avoiding the need to laser irradiate individual single cells. If appropriate RE (energy received per surface area) is applied, transient membrane perforation may result in areas where AuNPs are adjacent to the cell membrane [10,16]. Non-irradiated cells or cells without AuNPs attached [1] are not damaged by laser irradiation at the chosen RE. Thus, the method is suitable for selective manipulation of cells, both in temporal and spatial terms, because the timing as well as the area of irradiation can be selected individually. Available studies on the laser parameters reported in the literature employed cell lines rather than primary cells [1], or involved an fs-laser $(\lambda=780 \mathrm{~nm})$ [17]. For the latter, the optimal RE found for a carcinoma cell line was directly transferred to primary cells resulting in a transfection efficiency of $2.7 \%$ and cell losses of around 65\% [17]. For these cells the optimal RE has not been studied. In the present article, we describe for the first time the delivery of different molecules into primary human gingival fibroblasts (pHFIB-G) using AuNPs and laser irradiation. There is no information in the literature with regard to the REs that are associated with the highest number of perforated primary HFIB-G while maintaining cell viability. We assume a different reaction of primary human cells compared to those of a rather robust carcinoma cell line when being exposed to the interaction of AuNPs and laser pulses. This would indicate the necessity to carefully study possible negative side effects on the pHFIB-G and how to minimize them in order to reasonably transfer the results published earlier on this technique to clinical settings.

Our study hereby closes the important gap in applying this method in human cells and compares the findings in primary cells with those reported for cell lines. Thus, our two research questions were the following:

1. Can pHFIB-G be efficiently manipulated by ns-laser pulses interacting with AuNPs while maintaining high cell viability in comparison to a cell line (ZMTH3)?

2. Does laser irradiation allow spatial selectivity of treated cells, and can molecules be incorporated into pHFIB-G? 


\section{Materials and Methods}

\subsection{Materials and Cells}

We used primary human gingival fibroblast cells (HFIB-G, provitro GmbH, Berlin, Germany) cultured in Dulbecco's Modified Eagle Medium (DMEM) with 10\% fetal calf serum (FCS) and $1 \%$ penicillin/streptomycin (all obtained from Biochrom GmbH, Berlin, Germany). The cells were incubated at $37{ }^{\circ} \mathrm{C}$ and $5 \% \mathrm{CO}_{2}$. Depending on the experiments, they were either seeded in $35 \mathrm{~mm}$ glass-bottom dishes or in 24- or 96-well plates (glass bottom) one day before the experimental procedure.

To compare the laser parameters required for manipulation of $\mathrm{pHFIB-G}$ with those needed for cell lines, a canine pleomorphic adenoma cell line (ZMTH3) [18], provided from the Small Animal Clinic, University of Veterinary Medicine Hannover, Germany was used. ZMTH3 were cultured in Roswell Park Memorial Institute medium (RPMI-1640) with 10\% FCS and 1\% penicillin/streptomycin. Incubation, cell preparation, and laser treatment were the same for all experiments. The temperature was kept at $37^{\circ} \mathrm{C}$ throughout the experiment.

\subsection{Nanoparticles and Cell Manipulation}

We used $200 \mathrm{~nm}$ AuNPs (Kisker Biotech, Steinfurt, Germany) at a concentration of $0.5 \mu \mathrm{g} / \mathrm{cm}^{2}$. The cells were incubated with AuNPs for $3 \mathrm{~h}$. Within this time the particles sedimented on the cell surface. After incubation, the cell medium containing AuNPs was removed, retaining the sedimented particles on the cells. It was replaced by fresh DMEM containing the molecules to be delivered and $2 \%$ HEPES buffer solution (1 M, Sigma Aldrich, St. Louis, MO, USA) to maintain a physiological pH level during laser treatment. Then, the cells were irradiated with a laser.

\subsection{Laser Irradiation and Assessment of Molecules Uptake}

To perforate all cells within a short time, a pulsed HLX-G-F020 microchip laser (Horus Laser, Limoges, France) emitting at a wavelength of $532 \mathrm{~nm}$ was applied to the entire sample area by raster scanning the beam. Laser pulse duration was $1 \mathrm{~ns}$ and the repetition rate was $22.5 \mathrm{kHz}$. In the setup (Figure 1) the laser output power was adjusted using a half-wave plate $(\lambda / 2)$ and a polarizing beam splitter cube (PBS).

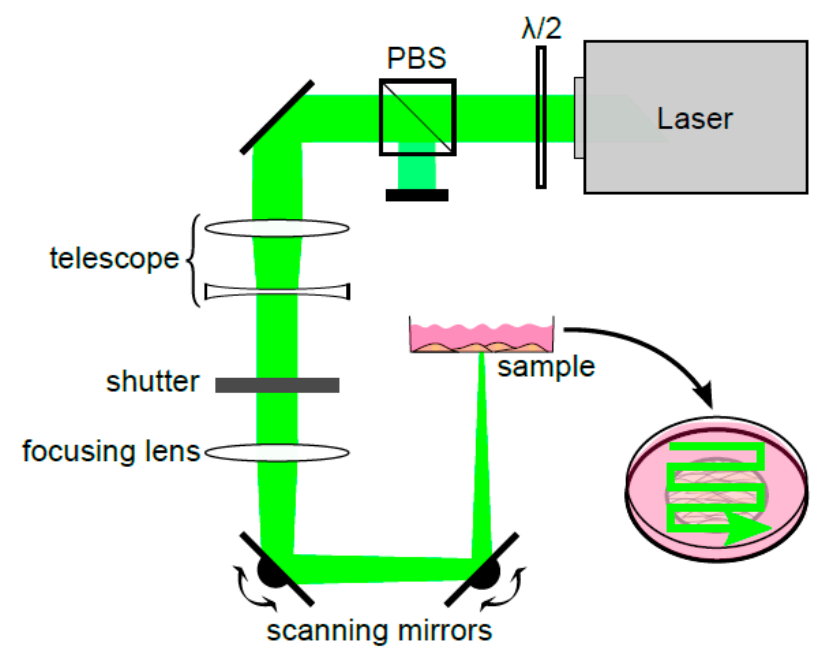

Figure 1. Schematic representation of the irradiation setup. For power adjustment, the combination of a half-wave plate $(\lambda / 2)$ and a polarizing beam splitter cube (PBS) was used. The laser beam was collimated with the help of a telescope and focused with a lens $(f=250 \mathrm{~mm})$. To treat all cells in the region of interest, scanning mirrors allowed the laser beam to raster scan the entire sample as shown in the inset on the lower right. 
A telescope collimated the laser beam. To focus the beam, a lens (focal length $f=250 \mathrm{~mm}$ ) was used resulting in a focus diameter of the beam of $100 \mu \mathrm{m}$ and entailing a large Rayleigh range of about $16.2 \mathrm{~mm}$. Hence, the REs in the whole sample region were assumed to be constant despite scanning the beam using two scanning mirrors ( $x$ - and $y$-direction). With this relatively weak focusing REs up to $35 \mathrm{~mJ} / \mathrm{cm}^{2}$ were obtained. Furthermore, high throughput was possible because irradiation of a cell growth area of $1 \mathrm{~cm}^{2}$ took approx. $60 \mathrm{~s}$ when scanning with a speed of $50 \mathrm{~mm} / \mathrm{s}$ and a lateral distance between two scanning lines of $33 \mu \mathrm{m}$.

After laser irradiation the cells were incubated for $10 \mathrm{~min}$ before washing them twice with phosphate-buffered saline. Next, fresh medium was added to allow continued culturing of cells or to determine the yield as described below. For quantification purposes each sample was handled in a separate well and all cells within one well were treated. When irradiating a user defined pattern of cells no quantification was performed.

To define the optimal laser parameters for the manipulation technique, fluorescent dyes were used. First, perforation efficiency (i.e., the number of cells successfully perforated but still viable) was determined. Therefore, $0.5 \mathrm{mM}$ of the cell-impermeable, fluorescent dye calcein (Sigma Aldrich, St. Louis, MO, USA) was dissolved in the extracellular medium before irradiation. It only enters the cytoplasm of those cells that were perforated during laser irradiation. After removing the extracellular calcein molecules, the successfully perforated cells fluoresced. Perforation efficiency was determined by counting the proportion of calcein-fluorescing cells. Simultaneously, the number of necrotic cells was determined. For quantification, the cells were first detached using TrypLE (Life Technologies, Carlsbad, CA, USA) and the TrypLE reaction was stopped by adding cell culture medium. Afterwards, the cells were centrifuged $(3 \mathrm{~min}$ at $300 \times \mathrm{g})$, the supernatant was removed, and the cells were resuspended in $20 \mu \mathrm{L}$ of medium. Then, $2.5 \mu \mathrm{M}$ of the fluorescent dye propidium iodide (PI, Life Technologies) was added to the cell suspension to stain necrotic cells. A Cellometer Vision 5x (Nexcelom Bioscience, Lawrence, MA, USA) was used to determine the total number of cells as well as the number of calcein- and PI-positive cells. For each parameter the experiment was performed on three different days.

For the experiment, pHFIB-G as well as the cell line ZMTH3 were irradiated with REs up to $35 \mathrm{~mJ} / \mathrm{cm}^{2}$. Non-laser-treated cells incubated with AuNPs and the delivery molecules served as negative control. When determining the proportion of perforated cells, only viable cells were counted. Perforation efficiency was defined as the percentage of cells containing calcein but no PI of the total number of treated cells. Thus, successfully perforated cells were those that were transiently permeabilized but were still able to seal their membrane afterwards so that no PI could enter. Non-necrotic cells were those that were successfully perforated but did not contain any PI. Long-term viability and cell proliferation were determined separately. To test whether larger molecules were delivered into the cells, fluorescein isothiocynate (FITC)-labeled dextrans of different molecular weights $(10 \mathrm{kDa}, 70 \mathrm{kDa}$, and $500 \mathrm{kDa})$ were dissolved in the cell culture medium. Preparation, laser irradiation, and washing steps were the same as those described above.

\subsection{Viability Assay}

Cell viability was determined by counting non-necrotic cells immediately after every experiment. Long-term influence of the laser treatment on the cells was determined by a proliferation assay using PrestoBlue (Life Technologies). The cells were seeded in a 96-well plate with $1.5 \times 10^{4}$ cells/well. Afterwards, cells were treated with AuNPs and laser as described above. To measure PrestoBlue reduction, the cell culture medium was removed from the wells and was replaced by fresh medium containing $10 \%$ PrestoBlue. Next, the cells were incubated at $37{ }^{\circ} \mathrm{C}$ and $5 \% \mathrm{CO}_{2}$ for $24 \mathrm{~h}$. Forty-eight hours, and $72 \mathrm{~h}$ after laser treatment absorbance of PrestoBlue at $570 \mathrm{~nm}$ was measured using a SPECTROstar Omega (BMG LABTECH, Ortenberg, Germany) plate reader. Emission at $600 \mathrm{~nm}$ was measured as a reference wavelength to normalize the absorbance. All values were background-corrected by subtracting the value for PrestoBlue reduction in medium alone. PrestoBlue reduction in non-treated cells (no AuNPs, no laser irradiation) was used as positive control. 
Two additional control groups were applied to identify the influence of laser irradiation and AuNPs separately: pHFIB-G treated with AuNPs but without laser irradiation, and cells treated without AuNPs, but irradiated with the highest RE. Cells were killed by incubating them in a 1:1 solution of methanol (99.6\%) and ethanol (99\%) for $10 \mathrm{~min}$ served as negative control. All parameters were analyzed in triplicates $(n=3)$ with each $1.5 \times 10^{4}$ cells per parameter.

To determine perforation specificity and efficiency for different molecules, the cells were treated as described above. To image the fluorescent cells an inverted microscope (Axiovert A.1, Zeiss, Oberkochen, Germany) and an EMCCD-Camera (iXon DU-885, Andor Technology Ltd., Belfast, UK) using the Andor Solis image acquisition software were used. All images were post-processed using ImageJ (U.S. National Institutes of Health, Bethesda, MD, USA) by enhancing their intensity and contrast as well as false color representation.

\subsection{Statistical Analysis}

The impact of laser irradiation on perforation efficiency and percentage of non-necrotic cells were analyzed in cooperation with the Institute of Biostatistics and Mathematical Modelling for different REs for pHFIB-G and ZMTH3 by using a non-parametric one-way analysis of variances (ANOVA) using ranks for non-normally distributed data.

\section{Results}

pHFIB-G and ZMTH3 were irradiated with REs up to $35 \mathrm{~mJ} / \mathrm{cm}^{2}$. The proportion of perforated living pHFIB-G increased with REs up to $20 \mathrm{~mJ} / \mathrm{cm}^{2}$ and decreased for higher REs (Figure 2a). At REs between $20 \mathrm{~mJ} / \mathrm{cm}^{2}$ and $35 \mathrm{~mJ} / \mathrm{cm}^{2}$ the difference between the control group of non-irradiated cells or cells irradiated with lower REs (e.g., $\left.15 \mathrm{~mJ} / \mathrm{cm}^{2}\right)$ was statistically significant $(p<0.05)$. Up to REs of $20-25 \mathrm{~mJ} / \mathrm{cm}^{2}$ the percentage of cells that successfully took up calcein increased up to a maximum of $85 \%$, while $97 \%$ of these cells were non-necrotic. As perforation efficiency was based on the proportion of living cells, it decreased in parallel with decreasing cell viability. Hence, REs of 20 to $25 \mathrm{~mJ} / \mathrm{cm}^{2}$ achieved highest perforation efficiency with high cell viability (Figure 2a). Comparing the results obtained for pHFIB-G with those obtained for a cell line (ZMTH3), we found that-in contrast to the finding for pHFIB-G-the proportion of necrotic ZMTH3 cells did not increase significantly at REs up to $35 \mathrm{~mJ} / \mathrm{cm}^{2}$ (Figure $2 \mathrm{~b}$ ). We ascribe the comparably high amount of calcein positive ZMTH3 without laser irradiation to the higher endocytic activity of tumor cells [19] during which they naturally take up molecules. Irradiating ZMTH3 with REs of $25 \mathrm{~mJ} / \mathrm{cm}^{2}$ and higher leads to a statistically significant $(p<0.05)$ increase in calcein uptake compared to non-irradiated cells. A maximum of $83 \%$ of ZMTH3 cells were perforated when the laser irradiated at a RE of $25 \mathrm{~mJ} / \mathrm{cm}^{2}$ while more than $99 \%$ of the cells were viable. Hence, $25 \mathrm{~mJ} / \mathrm{cm}^{2}$ was chosen as the optimal RE (Figure 2). Using this RE, pHFIB-G in a spatially defined cell growth area in shape of a tooth (Figure 3) were partly irradiated. Even though all of the pHFIB-G were incubated with AuNPs, only laser irradiated cells were perforated (Figure 3b,c). A magnified view of the boundary of such an irradiation pattern (Figure $3 b$ ) reveals no differences between the irradiated and non-irradiated area in bright-field images (Figure 3a).

Through the small membrane openings, extracellular medium diffused into the cells due to concentration differences which, therefore, took up the extracellular fluorescent dye. A bright-field microscopic image (see Figure 3a) revealed no obvious difference between irradiated and non-irradiated cells. However, fluorescence microscopic analysis of the same area showed that only a part of the cells was perforated (Figure 3b). Due to the relatively weak laser focusing applied a high throughput was achieved. The irradiation of an area of $1 \mathrm{~cm}^{2}$ took about one minute (Figure 3c).

Microscopic images confirm that fluorescently labeled dextrans with molecular weights of $10 \mathrm{kDa}$, $70 \mathrm{kDa}$, and $500 \mathrm{kDa}$ reached the cytoplasm if the optimal RE of $25 \mathrm{~mJ} / \mathrm{cm}^{2}$ was applied (see Figure 4; bright-field images a-c and the according fluorescent images $d-f$ ). 


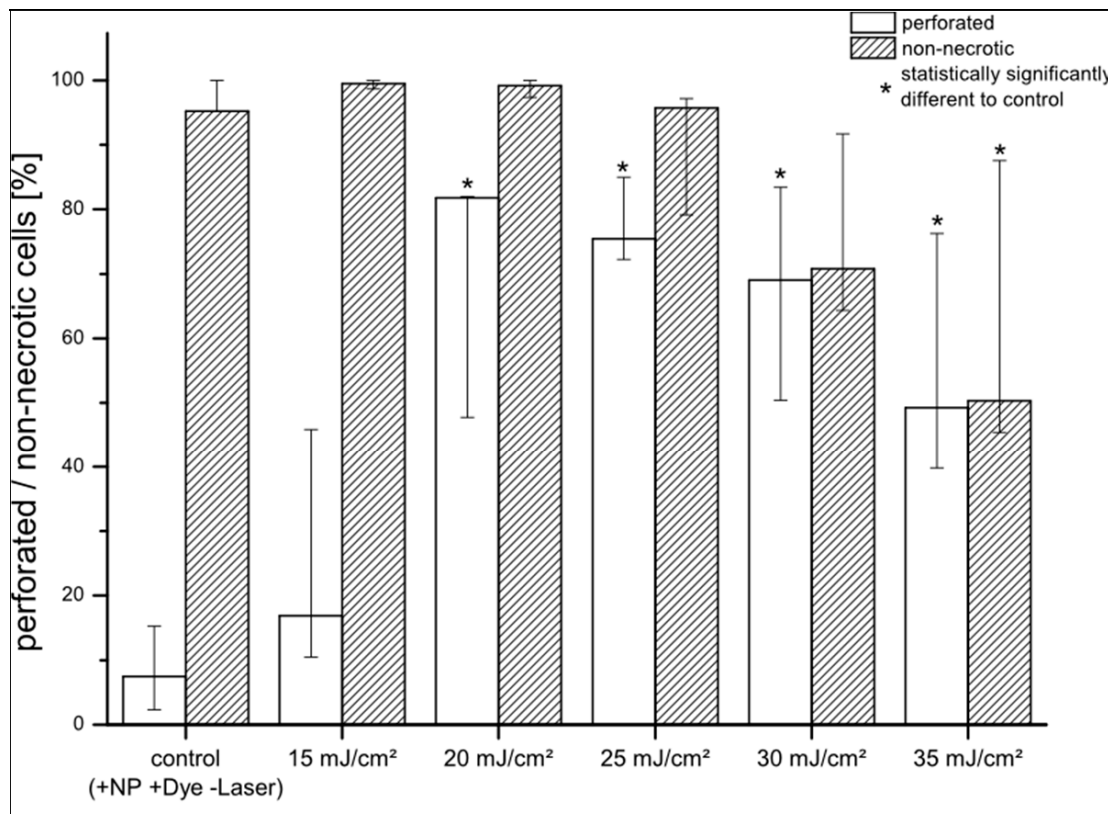

(a) pHFIB-G

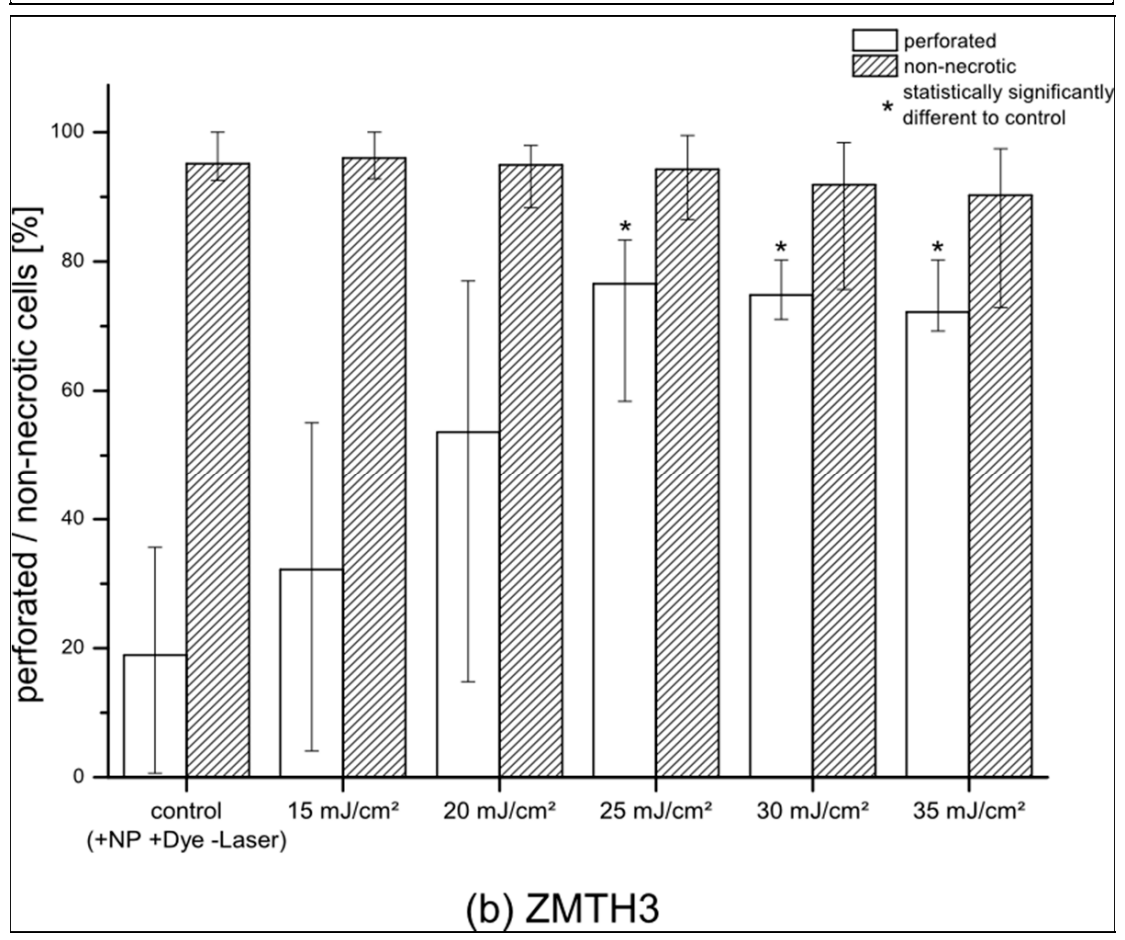

Figure 2. Perforation efficiency and percentage of non-necrotic cells irradiated with different radiant exposures (REs) for (a) pHFIB-G and (b) cell line ZMTH3 (statistical significance: $p<0.05$ ). For all parameters the median as well as minimum and maximum percentages are shown $(n=3)$. 


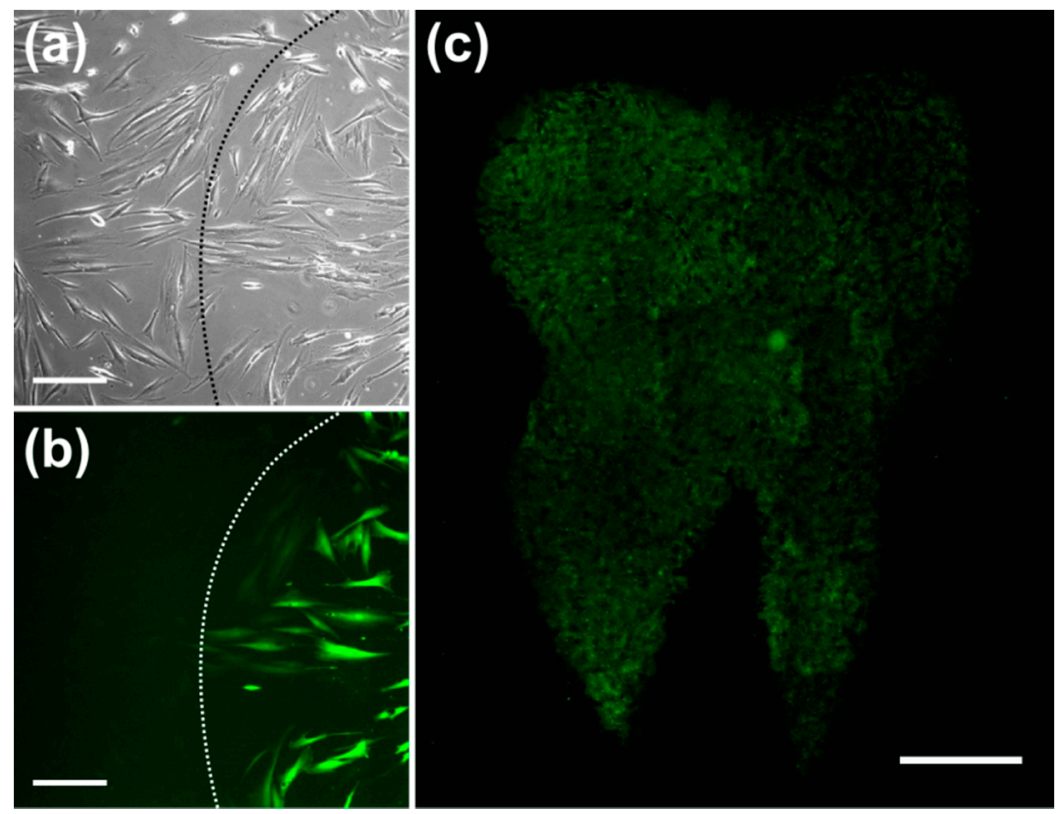

Figure 3. The technique allows spatially-specific irradiation. Only those pHFIB-G that were irradiated with a laser at a RE of $25 \mathrm{~mJ} / \mathrm{cm}^{2}$ were perforated and took up calcein (b, right side of dashed line); Bright-Field image of the same region (a) reveals that cells are evenly distributed and no differences between irradiated and non-irradiated area are visible. Still, only the pHFIB-G in the irradiated area were perforated (b); The irradiated cell area is a user defined pattern (e.g., in the shape of a tooth) (c). Scale bars: (a,b) $200 \mu \mathrm{m}$; (c): $2000 \mu \mathrm{m}$.
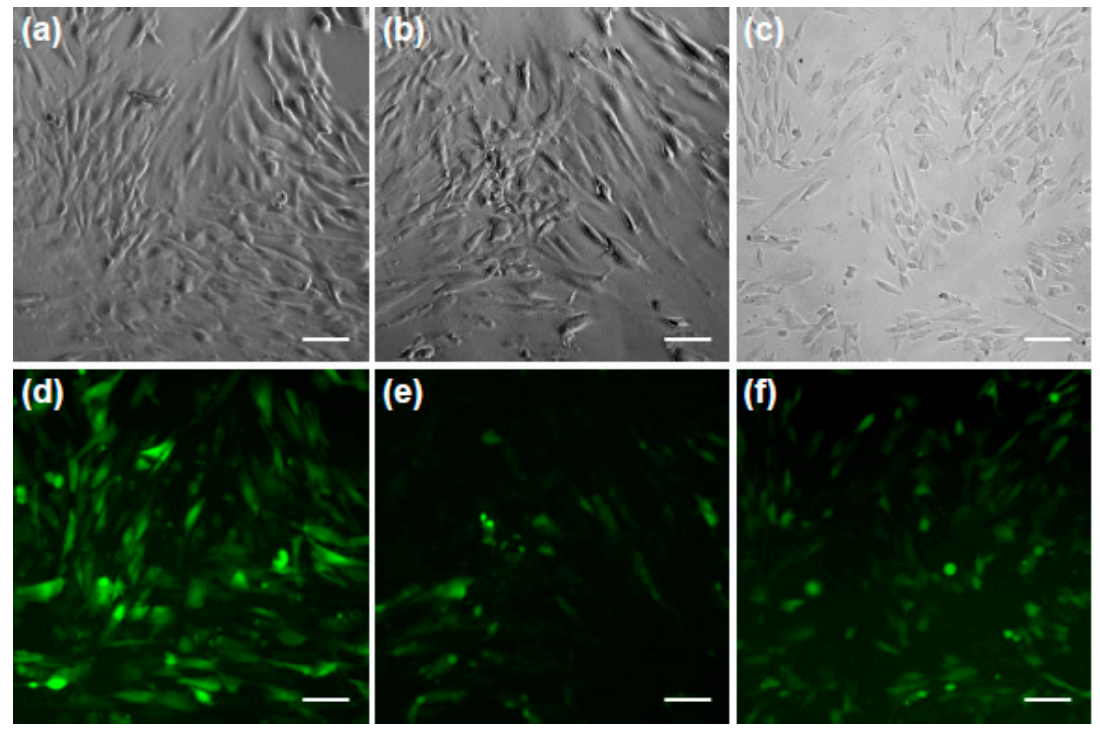

Figure 4. pHFIB-G irradiated with a RE of $25 \mathrm{~mJ} / \mathrm{cm}^{2}$ can also take up molecules larger than calcein. pHFIB-G took up fluorescently labeled dextrans with molecular weights (d) $10 \mathrm{kDa}$; (e) $70 \mathrm{kDa}$; and (f) $500 \mathrm{kDa}$ dextrans; as shown in the bright-field images (a-c); All scale bars: $35 \mu \mathrm{m}$.

We assessed long-term viability of pHFIB-G based on the reduction of Presto-Blue in the cell culture medium (Figure 5). Metabolic activity of the cells was determined at $48 \mathrm{~h}$ and $72 \mathrm{~h}$ after laser irradiation. No significant decrease of metabolic cell activity was observed up to $72 \mathrm{~h}$ after laser treatment, with the reduction of PrestoBlue at $48 \mathrm{~h}$ and $72 \mathrm{~h}$ found to be comparable. No trend of decreasing cell viability was seen when irradiating the cells with increasing REs. Similarly, the level of 
reduction for treated cells was in the same range as for non-treated cells. Reduction of PrestoBlue was $69 \%-92 \%$ in all samples except the negative control (cells killed with methanol/ethanol) (Figure 5).

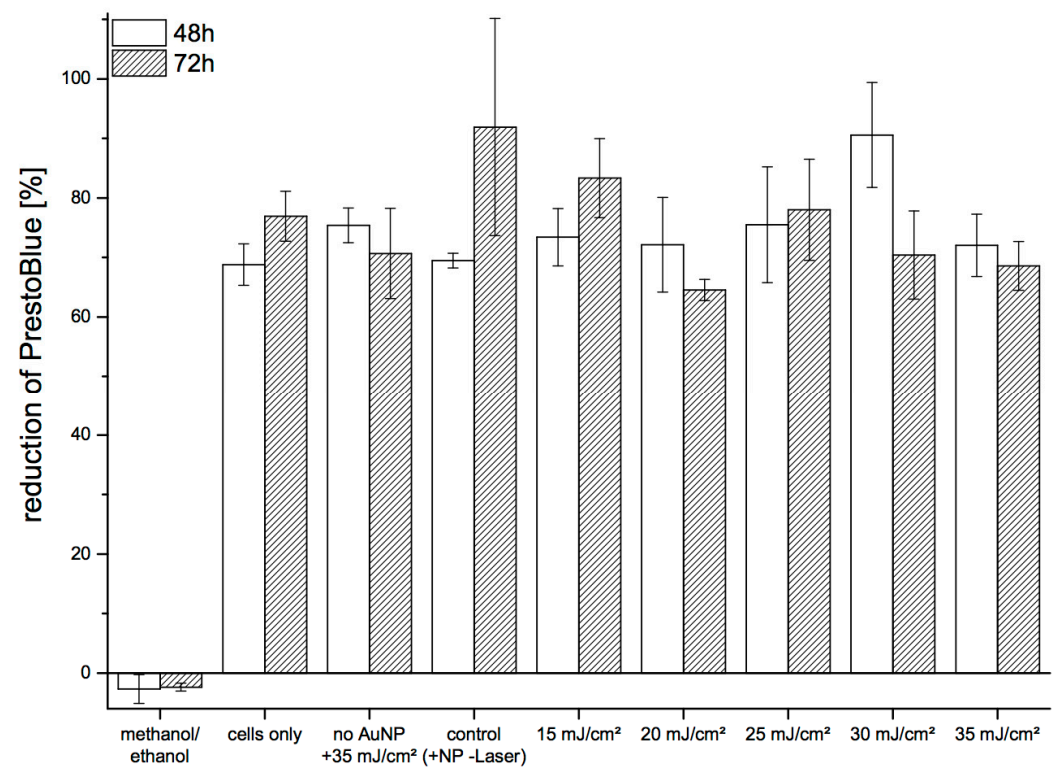

Figure 5. Long-term influence of the experimental procedure on metabolic activity of pHFIB-G measured by the reduction of PrestoBlue $48 \mathrm{~h}$ and $72 \mathrm{~h}$ after laser irradiation. All values are background-corrected for the blank (cell culture medium only). Means and SE are shown $(n=3)$.

\section{Discussion}

In the literature, the GNOME method used here is described as highly efficient and gentle to cells, and represents a promising tool in the search of medical applications of molecules [10]. Recent studies using on- and off-resonant laser pulses of different wavelengths systematically assessed the parameters that influence perforation rate and cell viability $[2,5,10,20]$. In contrast to continuous-wave laser exposure [21], pulsed laser irradiation as used in our experiments (interval between laser pulses: $44.4 \mu \mathrm{s}$ ) does not lead to accumulation of thermal effects because AuNPs are able to conduct the heat to their environment within nanoseconds [22]. Furthermore, conjugation of AuNPs with specific cell markers to further improve the selectivity is feasible. However, excessively high REs may induce irreversible damage to the cell membrane that cannot be repaired by the cell. This leads to necrosis and apoptosis of the targeted cells [12,15,23-26].

Successful transfection of cells with fluorescent siRNA as well as knockdown of the oncogene HMGA2 in tumor cells with specific siRNAs were demonstrated elsewhere [20]. Furthermore, the passive binding of AuNPs to the cell membrane has already been studied as well $[10,20]$. siRNA transfection models investigating future therapeutic strategies in dentistry were also recently investigated [26]. Authors found that p63 overexpression, for example, was associated with increased radioresistance and an unfavorable outcome for oral cancer patients [27]. Mueller et al. showed already that primary fibroblasts could be manipulated through nucleofection for transplantation purposes. These fibroblasts were treated with an efficiency of about $63 \%$ and transgene expression showed persistence up to day nine post-nucleofection [28]. The utilization of primary gingival fibroblast cells has many additional advantages: they are readily available in patients and thus represent a promising platform for cell-based therapies. However, no corresponding studies exist with these special gingival cells.

Perforation parameters for the cell line ZMTH3 using the GNOME method were, however, studied previously, and these were applied to different cell types without examining their optimal RE systematically $[10,20,29]$. We applied this technique on primary human gingival fibroblasts for the first 
time and studied the perforation parameters of primary human cells compared to those required for a cell line as we assume them to respond differently to the occurring side effects. The stated optimal $\mathrm{RE}\left(25 \mathrm{~mJ} / \mathrm{cm}^{2}\right)$ to perforate pHFIB-G coincided with the optimal RE for the cell line ZMTH3. This is in good accordance with the optimal RE of $20 \mathrm{~mJ} / \mathrm{cm}^{2}$ determined by Heinemann et al., who used a laser with pulse duration of $0.85 \mathrm{~ns}$ [10]. St-Louis Lalonde et al. found an optimal RE $55 \mathrm{~mJ} / \mathrm{cm}^{2}$ when applying $15 \mathrm{~ns}$ laser pulses [5]. Even though pHFIB-G seemed to be more sensitive than ZMTH3 cells, and their viability was reduced when using higher REs, perforation efficiencies with the same experimental conditions reached similar maximum values (85\% and $83 \%$, respectively). We ascribe the reduced viability for $\mathrm{pHFIB-G}$ to generation of ROS (Reactive Oxygen Species) during laser irradiation which can lead to cell death [24]. This effect is more pronounced in pHFIB-G as cancer cells are capable of dealing with higher ROS levels due to their higher antioxidant capacity [30]. Further optimization remains possible to increase the RE and the efficiency parameters. Solutions also exist to decrease the mortality triggered by molecule delivery. In this context recently synthesized and modified anti-oxidant molecules with ascorbic acid (PPAA) at various ratios showed collagen synthesis promoting property [31]. Weibel et al. investigated the laser-assisted delivery of Vitamin C, E, and Ferulic to achieve greater penetration in the tissue and stated an increased beta fibroblast growth factor expression [32]. Güney et al. succeeded to incorporate ascorbic acid (Vitamin C) in solid lipid nanoparticles (SLNs) by hot homogenization and to deliver them efficiently to cancer cells [33]. Our next step is therefore to assess the extent of which ascorbic acid could reduce cell death during molecule delivery by ns-laser pulses, while retaining high efficiency. These questions are also processed by different author teams, working on comparable models [2]. However, it must be stated, that in vitro experiments cannot be directly extrapolated to the intact in vivo situation, although we used the human cells most similar to the native tissue. The use of primary cells however presents huge donor to donor variability in terms of population doubling time and of morphology [2].

Hence, the technique seems not to be dependent on the cell type and can be used in cell lines as well as in primary human cells, even though they show different sensitivity towards the induced side effects. Spatial selectivity of the method was shown using the membrane impermeable dye calcein as a fluorescent marker. Only in irradiated regions did the absorption of laser energy by the AuNPs lead to membrane perforation. Absorption by phenol red as utilized in [3] can be neglected due to $10^{5}$ times smaller REs applied and lower absorption of phenol red at $532 \mathrm{~nm}$ compared to $488 \mathrm{~nm}$. Additionally, for ZMTH3 irradiation of cells without AuNPs were shown not to perforate the cellular membrane [1]. As analogously no effect was expected for pHFIB-G this was not examined in the present study.

Non-treated cells (no AuNPs, no laser irradiation) and cells not incubated with AuNPs but irradiated with laser at a RE of $35 \mathrm{~mJ} / \mathrm{cm}^{2}$ showed the same level of PrestoBlue reduction as did irradiated cells. Neither laser-irradiation nor AuNP-incubation or their interaction led to a decrease in cell proliferation and, consequently, long-term viability of pHFIB-G. Our findings prove that only irradiated cells were transiently perforated.

Heinemann et al. also showed that the absorbance spectra change with higher REs as AuNPs may melt, although the temperature induced by the RE applied are below the melting point of gold $\left(\sim 1063^{\circ} \mathrm{C}\right)[10,15]$. They proposed that thermal effects accompanied by multiphoton effects may be responsible for membrane perforation.

After an incubation time of $3 \mathrm{~h}$, the AuNPs applied sedimented and adhered to the cell surface, resulting in about six particles per cell for a AuNP concentration of $0.5 \mu \mathrm{g} / \mathrm{cm}^{2}$ [10]. Compared to off-resonance $(796 \mathrm{~nm}$ ) laser-mediated cell manipulation, this number of particles is low [20]. As no particle accumulation is necessary, defined perforation of the cell membrane in the vicinity of AuNPs is possible. Applying AuNPs conjugated to antibodies [24] or other cell-type specific markers may allow secondary spatial selection as only specific cells are targeted. Furthermore, we demonstrated that GNOME-treated pHFIB-G are also able to take up molecules at a size of up to $500 \mathrm{kDa}$. Hence, the results of delivering proteins and nucleic acids reported by Schomaker et al. [29] and Heinemann et al. [1,10] should be transferable to pHFIB-G using the same parameters. By utilizing 
media additives like antioxidants to reduce negative side effects of GNOME, it is likely to increase the viability and, hence, the transfection efficiency of primary cells. With this, the optimal RE for cells lines can be transferred to primary cells. This is promising for future applications in cellular therapies as the accessibility of gingival fibroblasts is high.

\section{Conclusions}

This study demonstrates that gold nanoparticle-mediated manipulation of primary human gingival fibroblasts ( $\mathrm{pHFIB-G)}$ using ns-laser pulses is a highly efficient method in cell perforation and is associated with low cytotoxicity. The best efficiency/toxicity ratio was obtained at a RE of $25 \mathrm{~mJ} / \mathrm{cm}^{2}$ with $85 \%$ efficiency and toxicity below $3 \%$.

It also anticipates what could be done on pHFIB-G to improve outcomes in future cell or tissue therapy.

Acknowledgments: We thank Hugo Murua Escobar, Hematology, Oncology and Palliative Medicine, University of Rostock, Germany (formerly Small Animal Clinic, University of Veterinary Medicine Hannover, Germany), for providing the ZMTH3 cells. Moreover, we gratefully acknowledge the support and assistance provided by Dipl.-Biol. Maja Weber and Udo Markert, Placenta-Lab of the Jena University Hospital, Germany, SPECTROstar Omega plate reader. Alexander Heisterkamp acknowledges the support of Excellence Cluster "REBIRTH" and funding initiative "Biofabrication for NIFE". Thanks are also due to Dipl.-Math. Natalie Filmann, Institute of Biostatistics and Mathematical Modelling, Faculty of Medicine, J.W. Goethe University, Frankfurt am Main, Germany for their statistical support, and to Silvia M. Rogers, MediWrite GmbH, Basel, Switzerland for editing and proofreading the manuscript.

Author Contributions: J.K., M.L.T.-M., K.W., A.H. and S.G.-S. conceived and designed the experiments; J.K. performed the experiments and analyzed the data; M.L.T.-M. helped analyzing the data; S.G.-S. contributed the cells, A.H. and S.G.-S. contributed all other reagents and materials; J.K., S.G.-S., S.R. and G.E.R. wrote the paper; all authors discussed the results, read and approved the manuscript.

Conflicts of Interest: The authors declare no conflict of interest.

\section{Abbreviations}

The following abbreviations are used in this manuscript:

$\begin{array}{ll}\text { AuNP } & \text { Gold nanoparticles } \\ \text { RE } & \text { Radiant exposure } \\ \text { pHFIB-G } & \text { Primary human gingival fibroblasts } \\ \text { ANOVA } & \text { Non-parametric one-way analysis of variances } \\ \text { ZMTH3 } & \text { Canine pleomorphic adenoma cell } \\ \text { GNOME } & \text { Laser-based gold-nanoparticle mediated manipulation of cells } \\ \text { FCS } & \text { Fetal calf serum } \\ \text { DMEM } & \text { Dulbecco's Modified Eagle Medium } \\ \text { RPMI-1640 } & \text { Roswell Park Memorial Institute Medium } \\ \text { PBS } & \text { Polarizing beam splitter cube } \\ \text { PI } & \text { Propidium Iodide } \\ \text { FITC } & \text { Fluorescein isothiocynate }\end{array}$

\section{References}

1. Heinemann, D.; Kalies, S.; Schomaker, M.; Ertmer, W.; Escobar, H.M.; Meyer, H.; Ripken, T. Delivery of proteins to mammalian cells via gold nanoparticle mediated laser transfection. Nanotechnology 2014, 25, 245101. [CrossRef] [PubMed]

2. Jumelle, C.; Mauclair, C.; Houzet, J.; Bernard, A.; He, Z.; Forest, F.; Peoc'h, M.; Acquart, S.; Gain, P.; Thuret, G. Delivery of Molecules into Human Corneal Endothelial Cells by Carbon Nanoparticles Activated by Femtosecond Laser. PLoS ONE 2015, 2, e0132023. [CrossRef] [PubMed]

3. Schneckenburger, H.; Hendinger, A.; Sailer, R.; Strauss, W.S.L.; Schmitt, M. Laser-assisted optoporation of single cells. J. Biomed. Opt. 2002, 7, 410-416. [CrossRef] [PubMed]

4. Yao, C.; Rahmanzadeh, R.; Endl, E.; Zhang, Z.; Gerdes, J.; Hüttmann, G. Elevation of plasma membrane permeability by laser irradiation of selectively bound nanoparticles. J. Biomed. Opt. 2005, 10, 064012. [CrossRef] [PubMed] 
5. St-Louis Lalonde, B.; Boulais, E.; Lebrun, J.J.; Meunier, M. Visible and near infrared resonance plasmonic enhanced nanosecond laser optoporation of cancer cells. Biomed. Opt. Express 2013, 1, 490-499. [CrossRef] [PubMed]

6. Lukianova-Hleb, E.Y.; Koneva, I.I.; Oginsky, A.O.; La Francesca, S.; Lapotko, D.O. Selective and self-guided micro-ablation of tissue with plasmonic nanobubbles. J. Surg. Res. 2011, 166, e3-e13. [CrossRef] [PubMed]

7. Doukas, A.G.; McAuliffe, D.J.; Flotte, T.J. Biological effects of laser-induced shock waves: Structural and functional cell damage in vitro. Ultrasound Med. Biol. 1993, 19, 137-146. [CrossRef]

8. Ogura, M.; Abernethy, A.D.; Blissett, R.D.; Ruggiero, K.; Som, S.; Goodson, J.M.; Kent, R.; Doukas, A.G.; Soukos, N.S. Photomechanical wave-assisted molecular delivery in oral biofilms. World J. Microbiol. Biotechnol. 2007, 23, 1637-1646. [CrossRef]

9. Terakawa, M.; Sato, S.; Ashida, H.; Aizawa, K.; Uenoyama, M.; Masaki, Y.; Obara, M. In vitro gene transfer to mammalian cells by the use of laser-induced stress waves: Effects of stress wave parameters, ambient temperature, and cell type. J. Biomed. Opt. 2006, 11, 014026. [CrossRef] [PubMed]

10. Heinemann, D.; Schomaker, M.; Kalies, S.; Maximilian, S.; Carlson, R.; Escobar, H.M.; Ripken, T.; Meyer, H.; Heisterkamp, A. Gold Nanoparticle Mediated Laser Transfection for Efficient siRNA Mediated Gene Knock Down. PLoS ONE 2013, 8, e58604. [CrossRef] [PubMed]

11. Hashimoto, S.; Werner, D.; Uwada, T. Studies on the interaction of pulsed lasers with plasmonic gold nanoparticles toward light manipulation, heat management, and nanofabrication. J. Photochem. Photobiol. C Photochem. Rev. 2012, 13, 28-54. [CrossRef]

12. Letfullin, R.R.; Joenathan, C.; George, T.F.; Zharov, V.P. Laser-induced explosion of gold nanoparticles: Potential role for nanophotothermolysis of cancer. Nanomedicine 2006, 1, 473-480. [CrossRef] [PubMed]

13. Nedyalkov, N.N.; Imamova, S.; Atanasov, P.A.; Tanaka, Y.; Obara, M. Interaction between ultrashort laser pulses and gold nanoparticles: Nanoheater and nanolens effect. J. Nanopart. Res. 2011, 13, 2181-2193. [CrossRef]

14. Pelton, M.; Aizpurua, J.; Bryant, G. Metal-nanoparticle plasmonics. Laser Photonics Rev. 2008, 2, $136-159$. [CrossRef]

15. Pustovalov, V.K.; Smetannikov, A.S.; Zharov, V.P. Photothermal and accompanied phenomena of selective nanophotothermolysis with gold nanoparticles and laser pulses. Laser Phys. Lett. 2008, 5, 775-792. [CrossRef]

16. Pitsillides, C.M.; Joe, E.K.; Wei, X.; Anderson, R.R.; Lin, C.P. Selective Cell Targeting with Light-Absorbing Microparticles and Nanoparticles. Biophys. J. Biomed. Opt. 2003, 84, 4023-4032. [CrossRef]

17. Schomaker, M.; Fehlauer, H.; Bintig, W.; Ngezahayo, A.; Nolte, I.; Escobar, H.M.; Lubatschowski, H.; Heisterkamp, A. Fs-laser cell perforation using gold nanoparticles of different shapes. Proc. SPIE Int. Soc. Opt. Eng. 2010, 7589. [CrossRef]

18. Murua Escobar, H.; Meyer, B.; Richter, A.; Becker, K.; Flohr, A.M.; Bullerdiek, J.; Nolte, I. Molecular characterization of the canine HMGB1. Cytogenet. Genome Res. 2003, 101, 33-38. [CrossRef] [PubMed]

19. Ortega, F.G.; Fernández Baldo, M.A.; Fernández, J.G.; Serrano, M.J.; Sanz, M.I.; Díaz-Mochón, J.J.; Lorente, J.A.; Raba, J. Study of antitumor activity in breast cell lines using silver nanoparticles produced by yeast. Int. J. Nanomed. 2015, 10, 2021-2031.

20. Schomaker, M.; Heinemann, D.; Kalies, S.; Willenbrock, S.; Wagner, S.; Nolte, I.; Ripken, T.; Escobar, H.M.; Meyer, H.; Heisterkamp, A. Characterization of nanoparticle mediated laser transfection by femtosecond laser pulses for applications in molecular medicine. J. Nanobiotechnol. 2015, 13, 1-15. [CrossRef] [PubMed]

21. Krpetić, Z.; Nativo, P.; Sée, V.; Prior, I.A.; Brust, M.; Volk, M. Inflicting controlled nonthermal damage to subcellular structures by laser-activated gold nanoparticles. Nano Lett. 2010, 10, 4549-4554. [CrossRef] [PubMed]

22. Furlani, E.P.; Karampelas, I.H.; Xie, Q. Analysis of pulsed laser plasmon-assisted photothermal heating and bubble generation at the nanoscale. Lab Chip 2012, 12, 3707-3719. [CrossRef] [PubMed]

23. Minai, L.; Yeheskely-Hayon, D.; Golan, L.; Bisker, G.; Dann, E.J.; Yelin, D. Optical nanomanipulations of malignant cells: Controlled cell damage and fusion. Small 2012, 8, 1732-1739. [CrossRef] [PubMed]

24. Minai, L.; Yeheskely-Hayon, D.; Yelin, D. High levels of reactive oxygen species in gold nanoparticle-targeted cancer cells following femtosecond pulse irradiation. Sci. Rep. 2013, 3, 2146. [CrossRef] [PubMed]

25. Peeters, S.; Kitz, M.; Preisser, S.; Wetterwald, A.; Rothen-Rutishauser, B.; Thalmann, G.N.; Brandenberger, C.; Bailey, A.; Frenz, M.; Rothen-Ruitshauser, B. Mechanisms of nanoparticle-mediated photomechanical cell damage. Biomed. Opt. Express 2012, 3, 435-446. [CrossRef] [PubMed] 
26. Zharov, V.P.; Galitovskaya, E.N.; Johnson, C.; Kelly, T. Synergistic enhancement of selective nanophotothermolysis with gold nanoclusters: Potential for cancer therapy. Lasers Surg. Med. 2005, 37, 219-226. [CrossRef] [PubMed]

27. Moergel, M.; Goldschmitt, J.; Stockinger, M.; Kunkel, M. $\Delta$ Np63 expression in four carcinoma cell lines and the effect on radioresistance-A siRNA knockdown model. Clin. Oral Investig. 2014, 18, 1259-1268. [CrossRef] [PubMed]

28. Mueller, C.T.; Thorwarth, M.; Schultze-Mosgau, S. Transgenic overexpression of VEGF164 enhances topical neoangiogenesis without detectable local or systemic side effects. Ann. Plast. Surg. 2010, 65, 85-90. [CrossRef] [PubMed]

29. Schomaker, M.; Killian, D.; Willenbrock, S.; Heinemann, D.; Kalies, S.; Ngezahayo, A.; Nolte, I.; Ripken, T.; Junghanß, C.; Meyer, H.; et al. Biophysical effects in off-resonant gold nanoparticle mediated (GNOME) laser transfection of cell lines, primary-and stem cells using fs laser pulses. J. Biophotonics 2015, 8, 646-658. [CrossRef] [PubMed]

30. Gorrini, C.; Harris, I.S.; Mak, T.W. Modulation of oxidative stress as an anticancer strategy. Nat. Rev. Drug Discov. 2013, 12, 931-947. [CrossRef] [PubMed]

31. Ambattu, L.A.; Rekha, M.R. Collagen synthesis promoting pullulan-PEI-ascorbic acid conjugate as an efficient anti-cancer gene delivery vector. Carbohydr. Polym. 2015, 26, 52-61. [CrossRef] [PubMed]

32. Waibel, J.S.; Mi, Q.S.; Ozog, D.; Qu, L.; Zhou, L.; Rudnick, A.; Al-Niaimi, F.; Woodward, J.; Campos, V.; Mordon, S. Laser-assisted delivery of vitamin C, vitamin E, and ferulic acid formula serum decreases fractional laser postoperative recovery by increased beta fibroblast growth factor expression. Lasers Surg. Med. 2016, 48, 238-244. [CrossRef] [PubMed]

33. Güney, G.; Kutlu, H.M.; Genç, L. Preparation and characterization of ascorbic acid loaded solid lipid nanoparticles and investigation of their apoptotic effects. Colloids Surf. B Biointerfaces 2014, 121, 270-280. [CrossRef] [PubMed]

(C) 2016 by the authors; licensee MDPI, Basel, Switzerland. This article is an open access article distributed under the terms and conditions of the Creative Commons Attribution (CC-BY) license (http://creativecommons.org/licenses/by/4.0/). 